\title{
Essential Surgery: The Way Forward: Reply
}

\author{
Jaymie Ang Henry ${ }^{1}$ Michael Cotton ${ }^{2}$
}

Published online: 10 September 2015

(C) Société Internationale de Chirurgie 2015

To the Editor,

We thank Monjok, E. for his comments on our article [1] regarding essential surgical training in Sub-Saharan Africa [2]. Indeed, the character and type of training; i.e., 3 versus 5 years, focused versus comprehensive, and rural versus urban posting; should remain within the purview of the local training institution which has the best gauge of the surgical needs of their community. Training patterns in high-income countries should merely serve as guides, but should not be expected to account for the contextual realities in low- and middle-income countries. Training general practitioners (GPs) or family medicine physicians (FPs) in surgery is not a novel phenomenon. GPs who underwent a 6-month training program in Ethiopia were found to be able to provide life-saving surgical care at a modest cost. [3] The challenge, however, lies in ensuring appropriate quality training with adequate delineation of scopes of competence and responsibility and ability to recognize the need to refer patients when needed, but also to recognize when referral itself may prove deleterious because of local conditions. There is a balance to be made on the amount of training and supervision provided for GPs, FPS, and non-physi- cian clinicians (NPCs), as well as adequate incentives to encourage retention.

We accept the feedback on the terminology 'Non-surgeon Physician' and agree that 'Surgical Medical Officer' is a viable option. However, many countries will wish to retain their own nomenclature. As validating a cadre of health worker necessitates political buy-in, Ministers of Health and other members of the health community need to be included in these discussions to achieve appropriate endorsement and legalization to achieve the ultimate goal of providing access to safe, quality, essential surgical care for all.

\section{References}

1. Monjok E (2009) The neglect of the global surgical workforce: experience and evidence from Uganda. World J Surg 33(1):150-151. doi:10.1007/s00268-008-9700-z author reply 2-3

2. Henry JA, Bem C, Grimes C, Borgstein E, Mkandawire N, Thomas WE et al (2015) Essential surgery: the way forward. World J Surg 39(4):822-832. doi:10.1007/s00268-014-2937-9

3. Loutfi A, McLean AP, Pickering J (1995) Training general practitioners in surgical and obstetrical emergencies in Ethiopia. Trop Doct 25(Suppl 1):22-26
Michael Cotton

mikeytha@gmail.com

1 International Collaboration for Essential Surgery (ICES), New York, USA

2 Service des Urgences, Centre Hospitalier Universitaire Vaudois, Rue Bugnon 46, 1011 Lausanne, Switzerland 